\title{
MAPEAMENTO TECNOLÓGICO PARA PURIFICAÇÃO DE BIOGÁS E SEU APROVEITAMENTO: PANORAMA MUNDIAL E INICIATIVAS NACIONAIS
}

\author{
S. BORSCHIVER ${ }^{1 \mathrm{e}}$ A.L.R.DA SILVA ${ }^{2} \mathrm{e}$ \\ ${ }^{1}$ Universidade Federal do Rio de Janeiro, Escola de Química, Departamento de \\ Processos Orgânicos/NEITEC \\ ${ }^{2}$ Universidade Federal do Rio de Janeiro, Escola de Química \\ Email para contato: suzana@eq.ufrj.br
}

\begin{abstract}
RESUMO - Diversas fontes de energia renováveis têm sido desenvolvidas e rapidamente disseminadas. Dentre as fontes alternativas em evidência, o Biogás surge como uma grande potencialidade nacional e, além de sua vantagem da aplicação final como substituinte do combustível fóssil, apresenta a vantagem da redução da emissão de metano produzido a partir da digestão anaeróbica de rejeitos urbanos e industriais, conforme ocorre nos aterros. Contudo, para viabilizar o aproveitamento energético deste gás formado, após a digestão anaeróbica se faz necessária uma etapa de purificação. O objetivo do presente trabalho é apresentar uma revisão das principais tecnologias utilizadas na purificação do biogás, as tendências mundiais e as iniciativas nacionais em relação ao aproveitamento deste biogás tratado.
\end{abstract}

\section{INTRODUÇÃO}

A emissão de gases poluentes, como dióxido de carbono e metano, pelo uso intenso de fontes de origem fóssil contribui para o alerta global em relação a mudanças climáticas e seus efeitos. Conforme divulgado no segundo semestre de 2013 pelo Painel Intergovernamental de Mudanças Climáticas (IPCC), formado por especialistas das Nações Unidas (ONU), a concentração de dióxido de carbono $\left(\mathrm{CO}_{2}\right)$ na atmosfera da Terra é a maior em pelo menos 800 mil anos.

Alternativamente, energia renovável tem sido desenvolvida e rapidamente disseminada, provendo uma fonte viável capaz de substituir a matriz fóssil. Energia solar, de hidrogênio, eólica, biomassa e biogás são exemplos dessas novas fontes de energia. Segundo a pesquisa realizada pela IEA Bioenergy Task 40 - divisão especializada em bioenergia da Agência Internacional de Energia (IEA, na sigla em inglês) o Brasil é apontado como o país que mais utiliza biomassa na produção de energia, sendo $16 \%$ do uso mundial no setor. Em seguida estão os EUA (9\%) e Alemanha (7\%).

O biogás é uma fonte de energia atrativa devido à possibilidade de ser gerado a partir da digestão anaeróbica de estrume, lodo de esgoto, lixo orgânico doméstico, industrial e agropecuário e de aterros sanitários. Além de ser uma fonte renovável de energia e um 
substituto para os combustíveis fósseis, o biogás também apresenta várias vantagens, incluindo a redução da emissão de metano para a atmosfera comparativamente ao tradicional gerenciamento de resíduos em aterros.

No Brasil, o biogás apresenta potencial de se tornar um dos três maiores combustíveis, mas as iniciativas para sua produção ainda são incipientes, especialmente se comparado com o panorama internacional.

O biogás de digestão anaeróbia de aterros consiste principalmente em $\mathrm{CH}_{4}$ e $\mathrm{CO}_{2}$ (Tabela 1). Componentes traços que estão frequentemente presentes no biogás são o vapor de água, sulfeto de hidrogênio, siloxanos, hidrocarbonetos, amônia, oxigênio, monóxido de carbono e nitrogênio. Para a conversão de biogás em biometano, duas etapas principais são executadas: (1) um processo de limpeza para remover os componentes traços (do inglês, cleaning process) e (2) um processo de ajuste do poder calorífico do gás (do inglês, upgrading process). $\mathrm{O}$ ajuste de poder calorífico é geralmente realizado a fim de cumprir as normas para o uso como combustível de veículo ou para a injecção na rede de gás natural.

Tabela 1- Composição do biogás

\begin{tabular}{lc}
\hline \multicolumn{1}{c}{ Componentes } & Composição \\
\hline $\mathrm{CH}_{4}($ vol-\%) & $60-70$ \\
$\mathrm{CO}_{2}($ vol-\%) & $30-40$ \\
$\mathrm{H}_{2} \mathrm{~S}(\mathrm{ppm})$ & $0-4000$ \\
$\mathrm{NH}_{3}(\mathrm{ppm})$ & $\sim 100$ \\
$\mathrm{~N}_{2}($ vol-\%) & $\sim 0.2$ \\
$\mathrm{O}_{2}($ vol-\%) & 0 \\
$\mathrm{H}_{2}($ vol-\%) & 0 \\
Outros hidrocarbonetos (vol-\%) & 0 \\
\hline
\end{tabular}

Diferentes métodos para limpeza do gás e ajuste de poder calorífico são utilizados. O objetivo do presente trabalho é apresentar uma revisão bibliográfica identificando as principais tecnologias utilizadas na purificação do biogás, delineando as principais tendências mundiais e apontando algumas iniciativas nacionais em relação ao aproveitamento deste biogás tratado. Para tal, foram utilizadas ferramentas de busca convencionais e científicas, de forma a identificar as principais publicações referentes ao tema.

\section{PRINCIPAIS CONCEITOS - LIMPEZA DO BIOGÁS E AJUSTE DE PODER CALORÍFICO}

A limpeza do biogás (do inglês, cleanup), consiste na remoção de impurezas, tais como sulfeto de hidrogênio, siloxanos, água, oxigênio, nitrogênio e partículas em suspensão presentes em diferentes concentrações, dependendo da composição do substrato a partir do qual o biogás foi produzido. A presença de impurezas, mesmo em baixas concentrações, podem afetar o equipamento causando problemas de corrosão e desgaste mecânico. Outro problema associado a impurezas é a emissão de poluentes indesejáveis, enquanto o biogás é 
queimado durante sua utilização. Alguns processos de ajuste de poder calorífico requerem um tratamento prévio para remoção de certas impurezas. As impurezas e as tecnologias de limpeza estão listadas na tabela 2.

Tabela 2 - Tecnologias de purificação de biogás

\begin{tabular}{|c|c|}
\hline Impureza & Tecnologia de limpeza \\
\hline Sulfeto de hidrogênio & $\begin{array}{l}\text { Precipitação / Absorção química / Adsorção em carvão ativado / } \\
\text { Tratamento biológico }\end{array}$ \\
\hline Siloxanos & $\begin{array}{l}\text { Resfriamento / Absorção em mistura líquida de hidrocarbonetos / } \\
\text { Adsorção em carvão ativado, alumínio e sílica gel / Co-separação } \\
\text { com sulfeto de hidrogênio }\end{array}$ \\
\hline Água & Resfriamento / Compressão / Absorção / Adsorção \\
\hline Oxigênio e Nitrogênio & Adsorção em carvão / Peneira molecular ou membranas \\
\hline Amônia & $\begin{array}{l}\text { Enquanto o gás é seco ou está no processo de ajuste de poder } \\
\text { calorífico }\end{array}$ \\
\hline Particulados & Filtro mecânico \\
\hline
\end{tabular}

O ajuste de poder calorífico consiste na remoção de dióxido de carbono que conduz a um aumento da concentração de metano e o aumento da densidade de energia. Muitas tecnologias para este processo estão disponíveis comercialmente e outros estão em fase de planta piloto.

\section{PRINCIPAIS PROCESSOS IDENTIFICADOS}

Os processos de limpeza do biogás já são consolidados e, portanto, grande parte dos estudos estão centrados nos processos de ajuste de poder calorífico. As tecnologias para ajuste de poder calorífico de biogás estão sendo mostradas na figura 1 e são classificadas em quatro grandes grupos de processos: adsorção, absorção, permeação e criogenia. Além desta classificação, foi possível perceber o grau de difusão das tecnologias identificadas. Neste sentido, os processos de adsorção e absorção foram classificados como processos consolidados e os processos de permeação e criogenia como processos novos. Vale mencionar que no corpo do trabalho ainda serão apontados alguns processos avançados, que se encontram em etapa de desenvolvimento. 


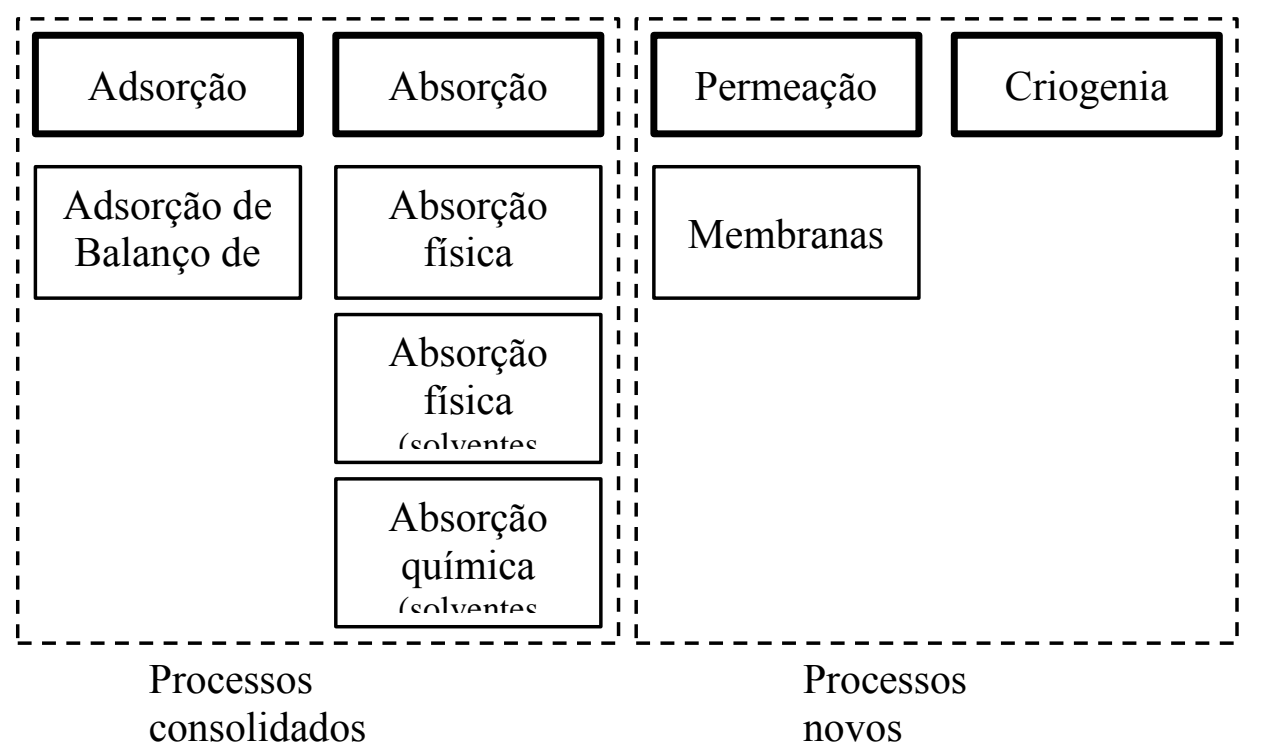

Figure 1 - Tecnologia de ajuste de poder calorífico de biogás.

A seguir, serão detalhadas as principais características destes processos.

\subsection{Adsorção de balanço de pressão}

A separação de gás utilizando adsorção se baseia na diferença de comportamento de adsorção dos diversos componentes do gás em uma superfície sólida sob alta pressão. Usualmente, diferentes tipos de carvão ativado ou peneiras moleculares (zeólitas) são utilizados como material adsorvente. Esses materiais adsorvem o dióxido de carbono do biogás de alimentação e, consequentemente, o enriquece em metano. Este sistema foi desenvolvido pela empresa suíça Acrion Systems. Nesse processo, o adsorvente é regenerado por um decréscimo sequencial de pressão antes de a coluna ser recarregada. O processo requer uma etapa preliminar de limpeza do gás, incluindo dessulfurização, resfriamento e remoção de água, antes da injeção do gás de alimentação na coluna de adsorção onde a peneira molecular está localizada, isto porque outras moléculas como o $\mathrm{H}_{2} \mathrm{~S}, \mathrm{NH}_{3}$ e $\mathrm{H}_{2} \mathrm{O}$ podem ser adsorvidas junto com o $\mathrm{CO}_{2}$. Neste processo, a concentração de biometano é superior a $96 \%$.

\subsection{Absorção}

O princípio deste processo é a baixa solubilidade do metano quando comparado com o dióxido de carbono. Neste sistema, o biogás encontra com um fluxo de líquido em uma coluna que é preenchida com um recheio de material plástico, de forma que o líquido retém alta concentração de dióxido de carbono, enquanto o gás tem sua concentração de metano aumentando. Existem três tipos de tecnologias de absorção que diferem pelo tipo de absorvente utilizado. 
Lavagem com água (do inglês, water scrubbing): o dióxido de carbono é mais solúvel em água que o metano, particularmente em baixas temperaturas e altas pressões. Diferentemente do processo de adsorção de balanço de pressão não é requerida uma etapa preliminar de limpeza do gás. Todavia outras moléculas como $\mathrm{H}_{2} \mathrm{~S}$ e $\mathrm{NH}_{3}$ podem ser absorvidas em paralelo, sendo que o $\mathrm{H}_{2} \mathrm{~S}$ necessariamente deve ser removido do gás de saída.

Lavagem física com solvente orgânico (do inglês, organic physical scrubbing): Este processo é similar à lavagem com água e também envolve interações físicas. Neste caso, o agente absolvente consiste em um reagente orgânico, como o polietileno glicol. Como na lavagem com água, $\mathrm{H}_{2} \mathrm{~S}, \mathrm{NH}_{3}$ e $\mathrm{H}_{2} \mathrm{O}$ também podem ser removidos, mas deve ser antes desta etapa de ajuste de poder calorífico. A solução de polietileno glicol pode ser regenerada por aquecimento ou despressurização. Alguns exemplos de tecnologias comercialmente diponíveis são Genosorb®, Selexol®, Sepasolv®, Rektisol® and Purisol@.

Lavagem química (do inglês, chemical scrubbing): Este método é similar aos outros descritos anteriormente, porém usa solventes baseados em aminas, como monoetanolamina (MEA), dietanolamina (DEA) e metildietanolamina (MDEA). Devido sua alta seletividade, a perda de metano é inferior a $0,1 \%$ e a concentração de metano no gás de saída é de, aproximadamente, $99 \%$.

\subsection{Permeação}

Este grupo de processos é representado pela permeação através de membranas e se baseia na diferença de permeabilidade dos componentes do gás através das membranas. Consequentemente, compostos menos permeáveis ficarão retidos na membrana, enquanto substâncias mais permeáveis passarão através dela. Como a permeabilidade é uma função direta da solubilidade química de cada componente da membrana, a permeabilidade dos componentes do gás na membrana depende de sua constituição. Existem duas técnicas de separação por membrana: a separação a alta pressão, o qual separa o dióxido de carbono e sulfeto de hidrogênio e é realizado em três fases produzindo biometano com $96 \%$ de pureza; adsorção gás-líquido, o qual é um novo processo desenvolvido usando uma membrana hidrofóbica de interface gás/líquido micro-porosa.

\subsection{Criogenia}

Esse processo é baseado na diferença entre o ponto de congelamento do metano ($\left.161^{\circ} \mathrm{C}\right)$ e do dióxido de carbono $\left(-78,5^{\circ} \mathrm{C}\right)$. O biogás é resfriado abaixo da temperatura a qual o dióxido de carbono condensa. Esse processo é operado em baixas temperaturas e altas pressões. A perda de metano é de 0,1\%-1\% e a pureza do gás de saída é de $99 \%$. Este sistema foi desenvolvido pela Gastreatment Services B.V.

Em Ohio, uma instalação de criogenia purifica gás de aterro. Todavia, como algum $\mathrm{CO}_{2}$ ainda permanece no biometano, uma etapa consecutiva de remoção de $\mathrm{CO}_{2}$ é necessária. Esse processo é de grande valor, pois o produto final, o biometano líquido é equivalente ao líquido 
de gás natural. Algumas estimativas mostram que o custo deste processo é comparável ao processo de absorção em água.

\subsection{Processos avançados em desenvolvimento}

Foi possível identificar processos apontados como tendências futuras, por estarem ainda em etapa de bancada. São eles:

Pulmão ecológico (do inglês, ecological lung): este processo usa a enzima carboanidrase para dissolver o dióxido de carbono, conforme mostrado na equação 1

$$
\mathrm{H}_{2} \mathrm{O}+\mathrm{CO}_{2} \Leftrightarrow \mathrm{H}^{+}+\mathrm{HCO}_{3}^{-}
$$

Esta enzima é presente no sangue, onde catalisa a reação que transforma dióxido de carbono em carbonato, que é então transportado aos pulmões onde esta enzima catalisa reação reversa. A empresa canadense, $\mathrm{CO}_{2}$ Solution Inc. desenvolveu esta técnica e depositou uma patente descrevendo o uso do biorreator com a enzima sendo utilizada para dissolver o dióxido de carbono. Um estudo executado por um grupo de pesquisa na Suíça mostrou que o biogás pode ser purificado a um nível de $99 \%$ de metano. Todavia, o custo de produção da enzima permanece alto e a tempo de vida da enzima imobilizada afeta a viabilidade do processo.

Enriquecimento de metano in situ (do inglês, in situ methane enrichment): a tecnologia consiste em fazer o lodo dos digestores circularem em uma coluna de dessorção para liberar o dióxido de carbono com auxílio de uma bomba de ar. A remoção contínua do dióxido de carbono aumenta a concentração de metano no biogás. De acordo com as simulações de processos, o biogás pode chegar a $95 \%$ de metano, com menos de $2 \%$ de perdas.

\section{TENDÊNCIAS DE UTILIZAÇÃO DOS PROCESSOS}

Atualmente, a principal técnica utilizada para ajuste de poder calorífico do biogás é a adsorção de balanço de pressão e os processos de absorção em água, solventes orgânicos e aminas. Entretanto, vale ressaltar que a melhor tecnologia escolhida deve se basear nos parâmetros específicos da planta.

A figura 2 mostra uma análise das plantas existentes, conforme reportado pelo International Energy Agency (IEA). $\mathrm{O}$ foco desta análise é o processo utilizado nestas plantas. De acordo com o gráfico, o processo mais difundido é o de lavagem (absorção em água $40 \%$ e absorção em aminas - 22\%), seguido pela adsorção de balanço de pressão (22\%). 

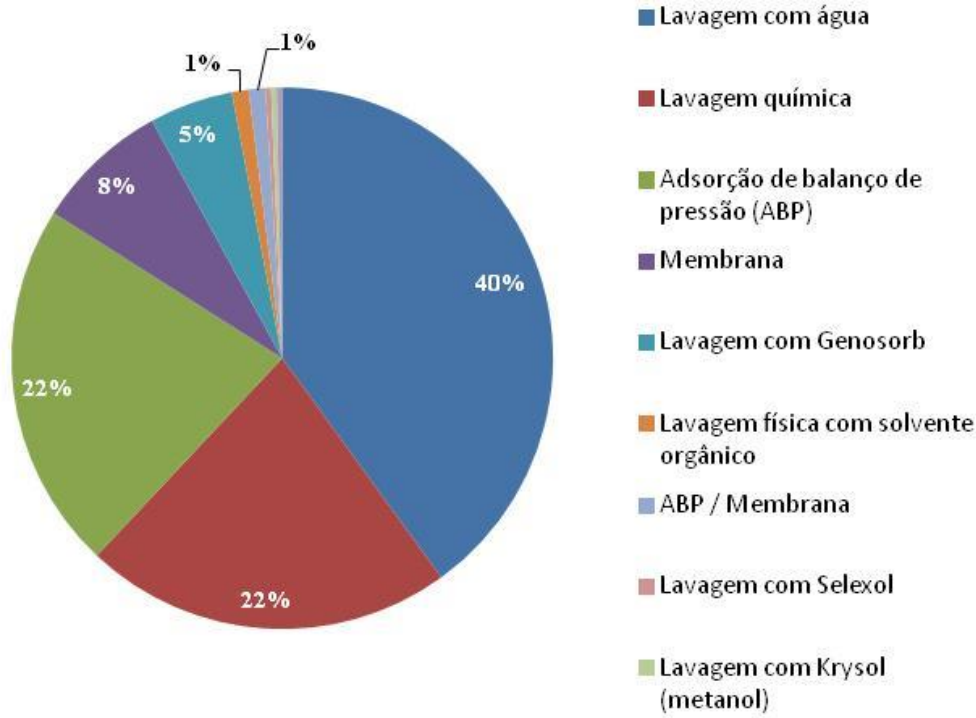

Figure 2 - Processos implementados nas plantas de tratamento de biogás existentes

\section{INICIATIVAS NACIONAIS}

Em dezembro de 2012, pelo Decreto no 58.659 , foi instituído o programa paulista de biogás, com objetivo de incentivar e ampliar a participação de energias renováveis na matriz energética do Estado de São Paulo, através das externalidades positivas da geração de gases combustíveis provenientes de biomassa e estabelecer a adição de um percentual mínimo de Biometano ao gás canalizado comercializado no Estado de São Paulo.

Vale mencionar que diversos projetos envolvendo a produção de energia a partir do biogás de aterro têm sido desenvolvidos no Brasil, não só no estado de São Paulo. Todos os projetos estão de acordo com as regras do Mecanismo de Desenvolvimento Limpo (MDL) do Protocolo de Quioto. Como exemplo, tem-se a produção de energia elétrica no aterro de Gramacho, RJ, com potência de 100.000 MW. O principal objetivo das atividades de projeto com gás de aterro de Gramacho é evitar a emissão de gases de efeito estufa através da captura, purificação e injeção do gás de aterro de Gramacho em uma rede de distribuição. A atividade de projeto MDL proposta consiste em capturar o gás gerado pelo aterro sanitário utilizando um sistema de captura e injetando-o em uma rede de distribuição de gás natural (depois de um processo de purificação), deslocando o uso de gás natural. A Petrobras receberá o gás melhorado do Projeto Gramacho de Gás de Aterro através de uma rede de distribuição de gás natural, por conseguinte misturando com gás natural. Esse tipo de projeto, ou seja, melhoria do gás de aterro para gás natural e injeção em uma rede de distribuição de gás natural é o primeiro de seu tipo no Brasil. Mesmo com estas iniciativas, a purificação de biogás para aplicação comercial ainda é incipiente no país, quando comparado à atividade internacional. 


\section{CONCLUSÕES}

O alerta global em relação às mudanças climáticas incentivam, em todo o mundo, o desenvolvimento das chamadas "tecnologias limpas", de forma a minimizar os danos ao meio ambiente e de alguma forma conter o avanço dos danos já causados. Grande parte dos danos gerados advém do uso de fontes fósseis para produção de energia, então, naturalmente, há uma movimentação em prol da identificação de fontes renováveis de energia, sendo o biogás uma das alternativas estudadas e com grande demonstração de viabilidade

O biogás é formado a partir da digestão anaeróbica dos rejeitos domésticos, industriais e agropecuários e, dependendo da natureza desta matéria prima, pode carrear consigo impurezas, sendo a principal delas o $\mathrm{CO}_{2}$. Assim, para aplicação final como fonte energética é necessária uma etapa de purificação, de forma a maximizar o teor de biometano, componente que efetivamente atua com a função energética.

Para eliminação dos elementos traços, como o $\mathrm{H}_{2} \mathrm{~S}, \mathrm{NH}_{3}, \mathrm{~N}_{2}, \mathrm{O}_{2}$ e $\mathrm{H}_{2}$ são utilizadas técnicas tradicionais para limpeza de gases, como os processos de absorção e adsorção. $\mathrm{O}$ desafio gira em torno do ajuste do poder calorífico do gás, isto é, a remoção do $\mathrm{CO}_{2}$ com consequente maximização do bio- $\mathrm{CH}_{4}$.

Neste estudo, foram identificados dois grupos principais de tecnologias para ajuste do poder calorífico do gás formado, do inglês, upgrading processes. O primeiro grupo se refere às tecnologias já consolidadas e amplamente difundidas, onde se encontram os processos de absorção (lavagem) e adsorção, com destaque para a adsorção de balanço de pressão. No segundo grupo estão os novos processos, onde muitos itens ainda se encontram em análise e otimização, como é o caso dos processos de permeação (membranas) e criogenia. Foram identificados também alguns processos classificados como "avançados", utilizando técnicas diferentes dos processos anteriores e ainda em fase de desenvolvimento. Um deles é o processo enzimático denominado "pulmão ecológico", em analogia com o processo que ocorre no organismo humano, onde a enzima carboanidrase é a responsável por capturar o $\mathrm{CO}_{2}$ do meio.

Diversas iniciativas nacionais para o uso do biogás de aterro foram identificadas, sendo destacadas neste artigo duas principais. A primeira delas oriundas do Governo Estadual de São Paulo que, por meio de um decreto, instituiu na cidade o Programa de Biogás, estimulando o uso deste como fonte energética. O segundo, na cidade do Rio de Janeiro, é uma parceria do aterro de Gramacho, o principal da cidade, junto a PETROBRAS, para aproveitar o gás formado na rede de gás natural da empresa. Apesar das iniciativas nacionais identificadas é importante salientar que a maior parte delas está sob a forma de projetos, em escala pequena. Isto é, as movimentações no Brasil ainda são incipientes comparadas ao exterior, onde muita tecnologia vem sendo desenvolvida e aprimorada. 


\section{REFERÊNCIAS BIBLIOGRÁFICAS}

ARESTA, Carbon Dioxide as Chemical Feedstock, Chapter 1, Wiley, 2010; BASU, S.; KHAN, A. L.; CANO-ODENA, A.; LIU, C.; VANKELECOM, I.F.G. Membranebased technologies for biogas separations. Chemical Society Reviews, Belgium, 2009.

BIOGAS HANDBOOK - Biogas Cleaning (Chapter 14) and Biogas Upgrading to methane (Chapter 15)

NEVES, V.L.V; Construção de biodigestor para produção de biogás a partir da fermentação de esterco bovino.Faculdade De Tecnologia De Araçatuba, São Paulo, 2010.

NYAGABONA, N.T.; OLOMI, D.R.; Analysis of value chain for biogas in Tanzania northern zone; University of Dar es Salaam, Tanzania, 2009.

PETERSSON, A.; WELLINGER, A. Biogas upgrading technologies - developments and innovations. IEA Bioenergy, 2009.

RYCKEBOSCH, E.; et. al.; Techniques for transformation of biogas to biomethane, Belgium, 2008.

http://www.brasil.gov.br/noticias/arquivos/2012/06/12/matriz-energetica-brasileira-tem-88-8de-geracao-de-fontes-renovaveis [Acesso 19/06/2013]

http://www.fragmaq.com.br/blog/energia-renovavel/biogas-no-brasil/[Acesso 19/06/2013]

http://www.al.sp.gov.br/repositorio/legislacao/decreto/2012/decreto\%20n.58.659,\%20de\%20

04.12.2012.htm [Acesso 19/06/2013]

http://www.estadao.com.br/noticias/vidae,concentracao-de-co2-na-atmosfera-e-a-maior-em-

800-mil-anos-diz-ipcc,1079435,0.htm) [Acesso 23/04/2014]

http://www.jornaldaenergia.com.br/ler_noticia.php?id_noticia=14825\&id_secao $=5$ [Acesso 23/04/2014]

http://mct.gov.br/index.php/content/view/344115/Projeto_Gramacho_de_Gas_de_Aterro.html [Acesso 23/04/2014]

https://maps.google.com.br/maps/ms?msid=204173588312141972413.0004c8df831ffbfb58df $5 \& \mathrm{msa}=0 \& \mathrm{dg}=$ feature [Acesso 23/04/2014] 